\title{
南开大学化学一流专业建设的探索与实践
}

叶芳, 王佰全, 李一峻, 郭东升 ${ }^{*}$

南开大学化学学院, 天津 300071

摘要: 经过多年的探索与实践, 南开化学在一流专业建设中已形成鲜明的专业特色, 本文从特色化人才培养模式、 科研创新能力培养、课堂教学质量督导等方面介绍南开化学一流专业建设的举措及成效。

关键词: 化学; 一流专业; 专业建设

中图分类号: G64; O6

\section{The Exploration and Practice of the Construction of the First-Class Chemistry Major of Nankai University}

\author{
Fang Ye, Baiquan Wang, Yijun Li, Dongsheng Guo * \\ College of Chemistry, Nankai University, Tianjin 300071, China.
}

\begin{abstract}
After years of exploration and practice, the chemistry discipline of Nankai University has exhibited distinctive characteristics during the construction of first-class major. This article introduces the construction of firstclass chemistry major in Nankai University from the aspects of characteristic talent training mode, scientific research and innovation ability training, and teaching quality supervision.
\end{abstract}

Key Words: Chemistry; First-class major; Major construction

\section{1 引言}

南开大学化学专业(后文简称 “南开化学” )历史悠久, 起源于1919年南开大学建校伊始的理科化 学门。南开大学建校之初, 张伯苓校长提出 “知中国, 服务中国” 的办学宗旨。杨石先老校长也提 出 “化学要为中国的经济繁荣学术进展做出更大的贡献”。化学专业建设始终秉承两位校长的教学 理念, 把国家发展需求放在人才培养首位, 以人为本, 因材施教。1991年被教育部批准为首批 “国 家理科基础科学人才培养基地” ，在后续评估中多次被评为优秀基地，2008年被教育部批准为高等 学校特色专业建设点, 2009年被认定为天津市品牌专业, 2009年入选首批 “基础学科拔尖学生培养 试验计划”，2017年入选 “双一流” 建设学科名单，2019年获评首批国家级一流本科专业建设点。

专业建设是建设高水平本科教育、培养一流人才的 “四梁八柱” [1]。南开化学始终以建设 “面向 未来、适应需求、引领发展、理念先进、保障有力” 的一流专业为目标, 全方位探索实践, 着力提 升人才培养质量。致力于培养具有化学及相关交叉跨领域创新研究、技术开发、专业教育、战略运 营与管理等潜质的化学专业型或复合型高级人才: 具有社会责任感、家国情怀和南开 “公能” 特 色, 良好的科技和人文底蕴, 全面发展的基本素质; 掌握现代化学相关的基础理论知识、实践技术 
和现代方法, 熟悉化学及相关领域的新进展; 具备持续自主学习、综合思辨、敢于实践、发现和解 决复杂问题的能力, 拥有较强创新意识、合作精神和国际视野。

\section{2 综合改革与建设的思路、举措和成效}

南开大学建校伊始就深深地打上了爱国主义的烙印。张伯苓校长的 “爱国三问” 被习近平总书 记称为 “这既是历史之问, 也是时代之问、未来之问” [2]。南开化学一直发扬南开大学公能兼备的育 人传统, 将课程思政贯穿一流人才培养全过程, 引导学生养成优良的道德品质和行为修养, 培养学 生强烈的爱国主义情怀和高度的社会责任感。开展以德为先, 能力为重, 全面发展, 勇于创新的 “公 能” 素质教育, 以 “公能” 为主线, 促进知行合一, 德、智、体、美的相互融合、协调发展, 为社 会主义事业培养高水平、高素质的化学专业人才。综合改革的一些具体的创新举措如下。

\section{1 大类培养与特色培养相结合}

南开化学因材施教, 根据学生个性化发展需求, 开创多层次、复合式、个性化培养模式。经过 多年探索实践, 开设大类培养、特色培养两种培养模式供学生自主选择, 如图1所示: 大类培养, 即 一、二、三年级 3 年修完专业必修课程, 四年级 1 年主要完成毕业设计和社会实践; 特色培养, 即一、 二年级 2 年修完专业必修课程, 三、四年级 2 年按照研究生模式培养, 进入校内外乃至国内外高水平 课题组进行集中科研训练。制定相应两年和三年分流培养的特色化教学计划, 学有余力的优秀学生 可根据自身实际情况选择特色教育培养模式。

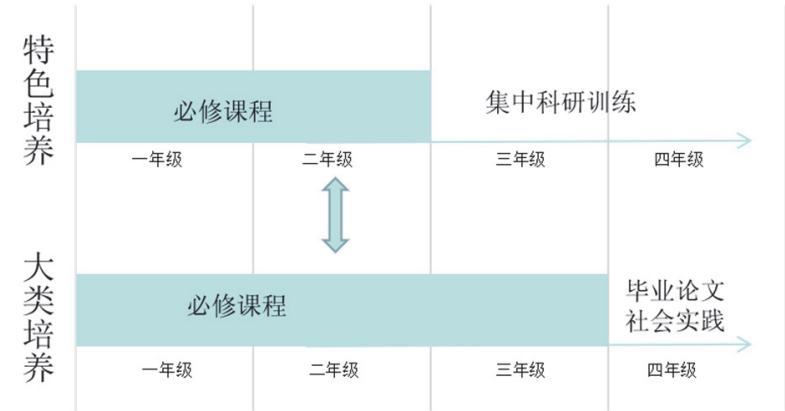

图1 大类培养与特色培养模式对比

引入动态进出机制, 大类培养、特色培养之间相互交叉, 无缝衔接, 打造多层次、个性化人才 培养环境。学生可随时根据自己的学习状态、适应程度调整自己的学习计划。南开化学制定系列政 策制度, 确保大类培养与特色培养模式可随时根据学生个人意愿切换、动态进出: 专业必修课程如 有机化学2-1、有机化学2-2、结构化学、化学概论等课程分批次上、下学期平行开设; 制定相关必修 课程成绩管理规定, 严格规定同一课程考核方式、平时成绩(包括期中考试)组成和比例一致, 平行班 平时成绩标准统一公平, 分批次开设课程两学期试卷难度相同, 确保成绩公平可比。课程、成绩标 准完全统一, 保证学生根据个人意愿, 无需申请, 无需课程替代、学分认证等程序直接实现大类培 养与特色培养之间的相互转换、动态进出, 充分尊重学生的个性化发展需求, 打造多层次、个性化 人才培养环境。得益于特色培养模式, 学生能够在大三大四参与海外实验室深度体验计划, 2015 级 共有 54 名学生到国外参加 3 个月以上的科研训练, 科研能力得到了锻炼提升。

\section{2 全面落实课堂教学督导}

南开化学严抓课堂教学质量, 重视本科教育教学各环节督导工作。努力以督导促改革, 引导教 师的专业发展和教学发展, 引导教师将主要精力投入教学和人才培养 ${ }^{[3]}$ 。坚持一个全面, 狠抓两个 重点, 注重三个反馈。一个全面: 组织学院督导组、听课专家对全院理论课程进行全覆盖的听课评 教活动。全部理论课程分组, 每组聘请三名专家对组内课程进行听课、打分、排序, 评出优、良、 合格以及不合格四等。两个重点: 重点关注新开课程以及上一学年专家听课合格但在组内排最后的 
课程, 组织督导组针对这两类重点课程进行听课督导, 提出改进意见, 帮助主讲教师提升教学效果。 三个反馈: 一是注重听课专家评教结果的反馈, 根据评教结果奖优罚劣, 获评优秀的教师在学院绩 效考核中予以工作量奖励, 对不合格的课程进行整改或停课; 二是注重学生评教结果反馈, 除在校 生的课程评教反馈外, 还通过座谈、问卷等形式收集毕业生反馈; 三是注重课程建设效果反馈, 制 定系列政策对获评 “一流课程”等荣誉的课程进行资助、支持。

在实验课程教学方面, 着重探讨摸索实验课程的教学质量评价体系, 通过举办教师实验技能系 列培训讲座和 “魅力化学实验课堂评比” 等活动, 以评促改, 积极提升教师实验教学水平; 鼓励实 验课程体系改革, 培养学生动手能力科研素养, 充分发挥专业实验课程体系在化学专业人才培养中 的重要作用, 形成更加完善的化学学科人才培养模式。

南开化学自2014年开展理论课程全覆盖的听课督导工作, 已累计督导听课1548门次, 针对性督 导288门次。2014年至今, 杨光明、孙宏伟、阮文娟、李一峻四位教授获评天津市教学名师, 共四名 教师获评宝钢奖优秀教师奖。周其林院士获评 “2018年度全国教书育人楷模”，2019年共五门课程 入选天津市线下、线上线下混合式、社会实践一流本科建设课程名单, 卓有成效地提升了课堂教学 质量。

\section{3 开展多层次、逐级深入的科研训练}

南开化学一直重视提升学生的创新意识以及科研能力, 所有科研实验室, 包括元素有机化学国 家重点实验室、药物化学生物学国家重点实验室以及其他教育部重点实验室, 均向化学本科学生开 放。南开化学设立了多层次、覆盖大学全过程的逐级深入的科研训练体系：大一上半年开展 “实验 室体验计划”, 组织学生选择不同方向、不同导师的课题组体验五次, 通过了解课题组的研究方向、 了解实验仪器的使用方法、观摩研究生的实验过程、旁听组会等形式感受科研氛围; 大一暑假开展

“暑期科研训练计划”, 开设讲座介绍实验室安全、实验室规范、文献检索、科研入门等, 学生选 择感兴趣的实验室进行为期四周的基础科研训练, 着重培养本科生科研能力、科研素养和科研兴趣; 大二开始组织学生参与国家大学生创新创业训练计划、天津市创新训练计划、南开大学百项工程, 学生在导师的指导下, 独立开展、完成科研训练项目; 大二暑假组织学生到中国科学院研究所进行 一个月的科研实习; 大三开始, 鼓励学生进入课题组, 进行全面的科研训练, 学生毕业论文全球做, 鼓励跨国、跨校、跨专业选择导师, 着力构建不同学科之间学术沟通与思想碰撞的环境, 促进学科 之间的交叉融合 ${ }^{[4]}$ 。

以2016级学生为例, 如图2所示: 大一全员参与 “我爱实验室” 活动; 大一暑假共 195 人参与暑 期科研训练计划, 约占总人数的 $70 \%$; 大二申请 “国家级大学生创新创业训练计划” 创新训练项目 7 项, “天津市大学生创新训练计划” 创新训练项目 40 项, 南开大学本科生创新科研 “百项工程” 项目 57 项，参与人数达到 256 人，约占总人数的 $90 \%$; 大二暑假共组织 30 人到中科院参观交流实习; 大三、大四大多数学生进行全面科研训练, 其中, 56 人在国外一流高校做 3 个月以上的科研训练, 26 人在北京大学、中国科学院上海有机化学研究所等国内知名高校研究所开展毕业论文。

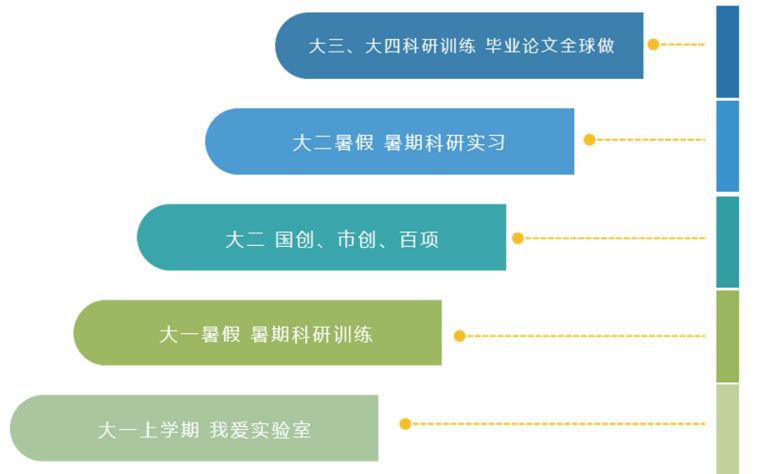

05

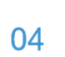

03

02

01
26 人在其他高校进行毕业论文,
56 人在国外做 3 个月以上科研

训练

30 人到长春应化所, 大连化物

所、上海有机所科研实习

“国创” 7项，“市创” 40 项，

"百项"：57 项，(参与人数

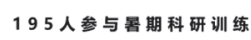

全员参与“我爱实验室”活动

图2 2016级学生科研训练情况 
经过多年探索与实践, 南开化学已形成良好的科技创新实践氛围, 每年参加科技创新活动的学 生人数占全年级人数的 $80 \%$ 以上, 学生创新意识和创新能力显著提升。本科生的 “新型高效离子液 体季铵盐在绿色有机合成中的应用研究” 获2017年 “挑战杯” 天津市特等奖和国家级二等奖; “铁 元素在催化形成碳-碳及碳-杂键中的新应用” 获2019年全国 “挑战杯” 竞赛二等奖; 由郭东升教授指 导, 本科生常宇轩、石麟、贾敬佩参与完成的创新实验 “联二炔囊泡的光致聚合、热致变色及其应 用” 获得首届全国大学生化学实验创新设计竞赛特等奖 ${ }^{[5]}$ 。近三年化学专业本科生获得各级创新项 目资助288项，2017-2019年发表学术论文162篇，授权专利19项。

\section{4 本土化培养与国际化培养并重}

南开化学注重学生的本土化培养和国际化培养, 为学生创造多种形式的交流机会, 鼓励学生到 国内外知名高校和科研院所进行实习。在本土化培养方面, 学院与中国科学院大连化学物理研究所、 中国科学院上海有机化学研究所、中国科学院长春应用化学研究所、中国科学院化学研究所、中国 科学院上海药物研究所、中国科学院理化技术研究所等签订联合培养本科人才合作协议, 建立科研 实习基地, 每年选拔 60 余名优秀本科生到科研实习基地的课题组进行科研培训、实习, 发挥各自优 势，联合培养，协同育人。

在国际化培养方面, 鼓励、资助学生参加国际一流大学的暑期学校和暑期科研项目, 特别是实 行海外实验室深度体验计划, 资助优秀学生到国际一流大学或研究机构的课题组参加 3 个月以上科 研训练。聘请海外大师为拔尖学生开设讲座、短期授课, 加大外籍教师引进力度, 逐步推进全英文 授课。与国际一流大学签订合作协议, 深化国际合作培育, 全面搭建高水平科研平台, 拓展学生科 研视野。通过一系列国际交流与合作培育举措, 2014、2015、2016级本科生在学期间出国交流累计 达 220 余人次, 约占年级总人数的 $28 \%$ 左右。

对于最后的毕业论文工作, 鼓励、支持学生联系国内外著名大学、研究机构高水平导师, 进入 其课题组开展毕业论文, 实现了毕业论文全球做。南开化学的本科生综合素质突出, 受到国内外一 流大学、研究院所的广泛认可。诺贝尔奖获得者Stoddart教授在给肖奎(学号1410823)的反馈信中指 出: “肖奎同学将带着我的最高评价和推荐回到他的母校南开大学, 他对科研工作的奉献和实践都 能称得上是真正的典范, 他具备一个年轻科学家所追求的所有品质, 我坚信肖奎同学将成为一名杰 出的科学家”。南开化学近三年毕业生情况如图3所示, 2017-2019届毕业生约有60\%学生继续深造, 有近 $20 \%$ 毕业生分别赴斯坦福大学、牛津大学、加州理工大学、剑桥大学、耶鲁大学、斯克里普斯研 究所等国际一流大学研究所继续攻读学位, 而 $40 \%$ 左右毕业生选择在清华大学、北京大学、南开大 学等国内一流大学和科研院所继续深造。

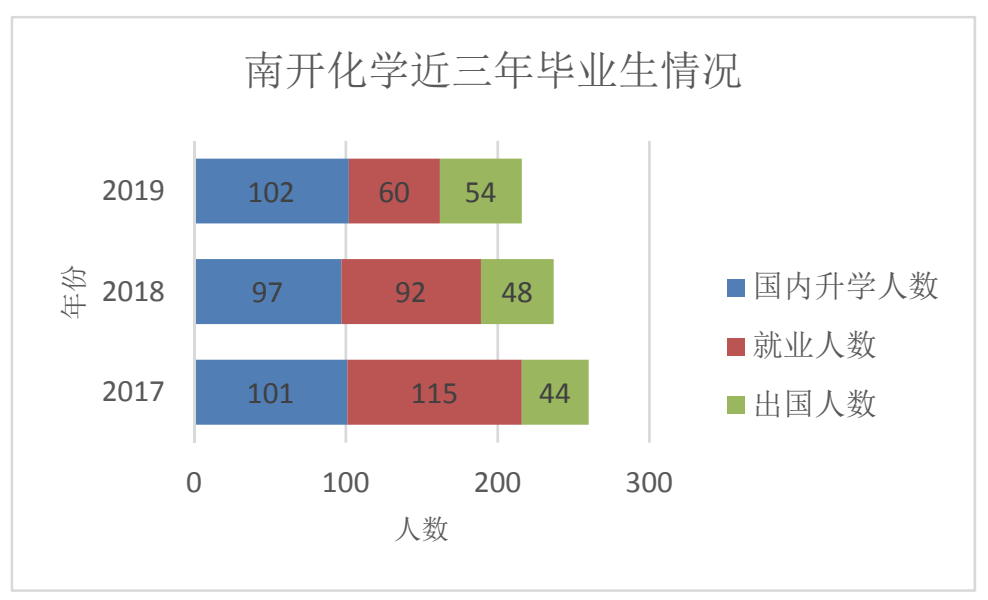

图3＼cjkstart南开化学近三年毕业生情况 


\section{3 结语}

南开化学在2019年获评首批国家级一流本科专业建设点。在今后的专业建设中, 我们将继续提 升教师育人意识, 提升人才培养质量, 在肯定既往成果的同时也不断反思自己的不足。2020年受新 冠疫情影响, 本科教育教学工作面临很多新的挑战, 围绕信息化、网络化和智能化的社会需求, 南 开化学拟通过线上、线上/线下混合等形式进行课程改革, 建设更多优质在线课程, 形成课程群; 建 设虚拟仿真实验项目, 将理论教学和实验教学更高效地融合; 还将持续开拓国际化格局, 加大外籍 教师引进力度, 逐步推进全英文授课, 提升专业实力, 逐步吸纳更多留学生, 打响南开化学国际品 牌, 扩大国际影响力。

\section{参 考 文 献}

[1] 关于加快建设高水平本科教育全面提高人才培养能力的意见. [2018-10-08]. http://www.moe.gov.cn/srcsite/A08/s7056/201810/t20181017_351887.html

[2] 一项历史性工程一一习近平总书记调研京津冀协同发展并主持召开座谈会纪实. 人民日报, 2019-01-20, (1).

[3] 张树永. 中国大学教学, 2018, No. 3, 25.

[4] 王佰全. 大学化学, 2019, 34 (10), 18.

[5] 常宇轩, 石麟, 贾敬佩, 李一峻, 郭东升. 大学化学, 2020, 35 (4), 96. 